\title{
Role and Importance of Training Climate for Effective Training Programs
}

\author{
Prof. Anu Singh Lather \\ Dean, University School of Management Studies GGS IP University \\ Kasmere Gate Delhi India \\ Tel: 91-11-23900253Ｅ-mail: anusinghlather@gmail.com
}

Harsh Sharma (Corresponding author)

Jaypee Business School JIIT University

Sector 62 Noida India

Tel: 91-11-25558363Ｅ-mail: harsh.sharma_h@ rediffmail.com

\begin{abstract}
It is widely recognized that training has to come out of its traditional dormant state to the main stream of corporate functioning and contribute proactively towards attainment of organizational objectives. However, this long overdue importance will be short-lived if training professionals do not show commitment towards enhancing value of training. The process of training delivery is mediated by pre and post delivery factors which have an influence in constructing favorable or unfavorable training climate. This paper addresses the all important issue of training climate and the role played by various stakeholders in developing this. The theoretical model and assumptions are substantiated through case examples.
\end{abstract}

Keywords: Training Climate, Strategy, Evaluation 


\section{Introduction}

Increasing focus on alignment of training strategy with organizational strategy is putting renewed emphasis on identifying factors responsible for successful implementation of learning acquired through training in organizational settings. In Indian organizations strategic integration of human resource management has acquired pace after the liberalization of economy in 1991.(Budhwar and Sparrow, 1997). For positioning training better, i.e., for ensuring its best possible fit with ongoing change strategies, policy makers and change managers set the specifications that training is to achieve and also to time, numbers, cost and other considerations to suit (Lynton \& Pareek, 2000; Kirkpatrick, 1975).

Training without appropriate mechanism for implementation is not worthy of valuable and scarce organizational resources. Primary requirements for effective training are assessment of needs, clear training policy, and support of the management, co-operation of the managers and adequate finance and resources (Fill and Mullins 1990). The goal of strategic, skill-building training is to produce meaningful, lasting behavior change in the participants who attend the sessions. (Crosbie, 2005) Many authors have emphasized on importance of organizational context in effective delivery of training. Most of these attempts to define effective training imply that it is often an attempt to change the way the organization functions (Philips, 1997; Bramely, 1989). However, training professionals have little control or influence on the working of organization. They can improve effectiveness by working on other factors which may lead to effective training. It is argued that impact of training is moderated by multiple factors. Success depends not only on effective training delivery but also on such important elements as expert facilitation, contextual awareness, formal and informal support, real-world application, self-study, self-awareness, stress and celebration (Crosbie, 2005).

All these factors have an integrated cumulative impact on ultimate success or failure of the training but they can be classified in three categories for the for the purpose of diagnostic understanding and analysis. These categories correspond to the chronological origin of the factors at different stages. These stages are Before Training, During Training, After Training or Before Entry (Reentry) in the workplace, upon Exiting The Workplace .(Nicholas 1992 \& Birmani and Seth. 1985). We are concentrating on first three basic categories which are named as Pre Training, Training and Post Training..

Training professional enjoy some level of control on Pre Training and Training stages though their intervention in post training stage is minimal. This creates an anomaly which has negative repercussions on training effectiveness. Training Climate in training room is the out come of interaction of three stage factors. If these factors and their interaction with Training Climate are well understood by training professionals then it may lead to better delivery of training. In the following discussion, elaboration on the Training stages and training climate is being done and a model is proposed to understand interwoven relationship. 


\section{Training Stages}

\subsection{Pre Training Stage}

It corresponds to planning, acquisition of necessary resources and identifying post training evaluation parameters. Planning for training includes setting of narrow and broad objectives, identification of training tools and trainers, selection of training methodology, scheduling etc. Acquisition of resources involves collecting and arranging all identified required resources. It is quintessentially important to identify post training evaluation factors at pre training stage itself. It gives more credibility to training effort and helps trainer in orienting training towards attainment of organization objectives. Pre training stage is crucial as many important factors can not be varied later during training stage if it was felt that some change is required.

\subsection{Training Stage}

This is the delivery stage of training program. Successful delivery is dependent on trainees, trainers and most importantly on training climate. As training program is developed keeping in mind organizational needs and constraints, it is of paramount importance that these needs and constraints are kept in mind while delivering the training program. It is important that trainees not only learn the concepts or knowledge dimensions in a generic way but they should also imbibe organizational context and background. Training climate is dealt with in detail in this paper later on.

\subsection{Post Training Stage}

This is the implementation stage. It is crucial that all the learning is implemented and feed back taken so as to understand impact of training and help in designing and improving future training programs. Without an effective post training strategy and support, training program will not lead to desired results. Post Training support includes availability of resources required and facilitation of implementation of learning. This requires sensitization of all the members in reference group of trainees about the training objectives and ensuring their whole hearted cooperation.

Out of these stages, the paper deals with the 'Training stage', however training stage can not be studied in isolation. It is structured during pre - training stage and implemented during post - training stage. In this stage, the crucial factors are trainee and trainer relationship and how they connect with the training objectives and organization objectives. Primarily this relationship coupled with contextual factors lead to favorable or unfavorable training climate.

\section{Training Climate}

Training climate is the result of interaction between trainees and trainers in the context of 
training environment. Climate can either be favorable or unfavorable for effective delivery of training. (Lynton \& Pareek, 1990) favorable and unfavorable climate ostensibly is the result of feelings of trainers and trainees. But these feelings are moderated by other factors having genesis in pre and post training stages. Favorable climate is manifested high degree of team work, trust and commitment on the part of both trainer and trainee. Unfavorable climate is expressed in low trust, unhealthy competition and lack of interest on the part of stakeholders.

Table 1: Factors affecting participants' and trainers' feelings

\begin{tabular}{|c|c|}
\hline Participants' Feeling & Trainers Feelings \\
Relevant Factors & Relevant factors \\
\hline$\bullet$ Individual factors & $\bullet$ Trainer related factors \\
- Group factors & $\bullet$ Trainee related factors \\
- Pedagogical factors & $\bullet$ Organization Factors \\
- Organization factors & \\
\hline
\end{tabular}

\subsection{Participants' Feelings}

These are the outcome of interaction between individual, group, training and organizational factors. Individual factors are related with individual priorities, personal life situation and comfort level. Group factors include the sense of relatedness in the group, dynamics of the group, prior association among group members. This contributes to the participants feelings in training environment. Pedagogical factors which contribute are trainers' ability to relate, timing, structuring, scheduling and methodology. Organizational factors are perceived organizational support, work context in which training will be implemented and perceived positive or negative consequences of training on performance enhancement and assessment. (Refer to Table 1)

\subsection{Trainer's Feelings}

These are dependent on factors classified as Trainer related, Trainee related and organization related. Trainer related factors are dependent on trainer's command over training subject, level of motivation and prior preparation. Trainee related factors are participants' prior understanding of the subject and involvement in the training program. Organization factors are resources and time commitment and perceived importance given to training. (refer to Table 1)

Participants' and trainers feelings mediate to construct a favorable or unfavorable training climate. Factors affecting participants' and trainers' feelings are summarized in Table I. Favorable climate leads to high collaboration between trainer and trainees whereas unfavorable climate results in low motivation and defensive behavior. 
It is imperative on the part of organization to ensure that all the three stakeholders i.e. organization; trainer and trainee behave in the manner so as to facilitate construction of favorable climate. Since organization has the biggest stake in successful conclusion of training, it is the prime responsibility of training mangers to evaluate the factors which lead to evolution of favorable or unfavorable climate. If this responsibility is not taken up with the seriousness it deserves then the outcomes can be quite disastrous.

\section{Training Stages and Training climate- An Interactive Model}

As explained above training climate is the result of interaction between Participant's Feeling and Trainer's Feeling, however, each factor responsible for participant and trainer's feeling manifests itself at different stages of training. Understanding this relationship is important from diagnostic point of view. Complexities and subtleties of this relationship would give us ample scope of evaluating strength of a training program as well as help us in taking corrective action. The relationship model is proposed in figure 1.

Figure I: Training Stages and Training Climate- An Interactive Model

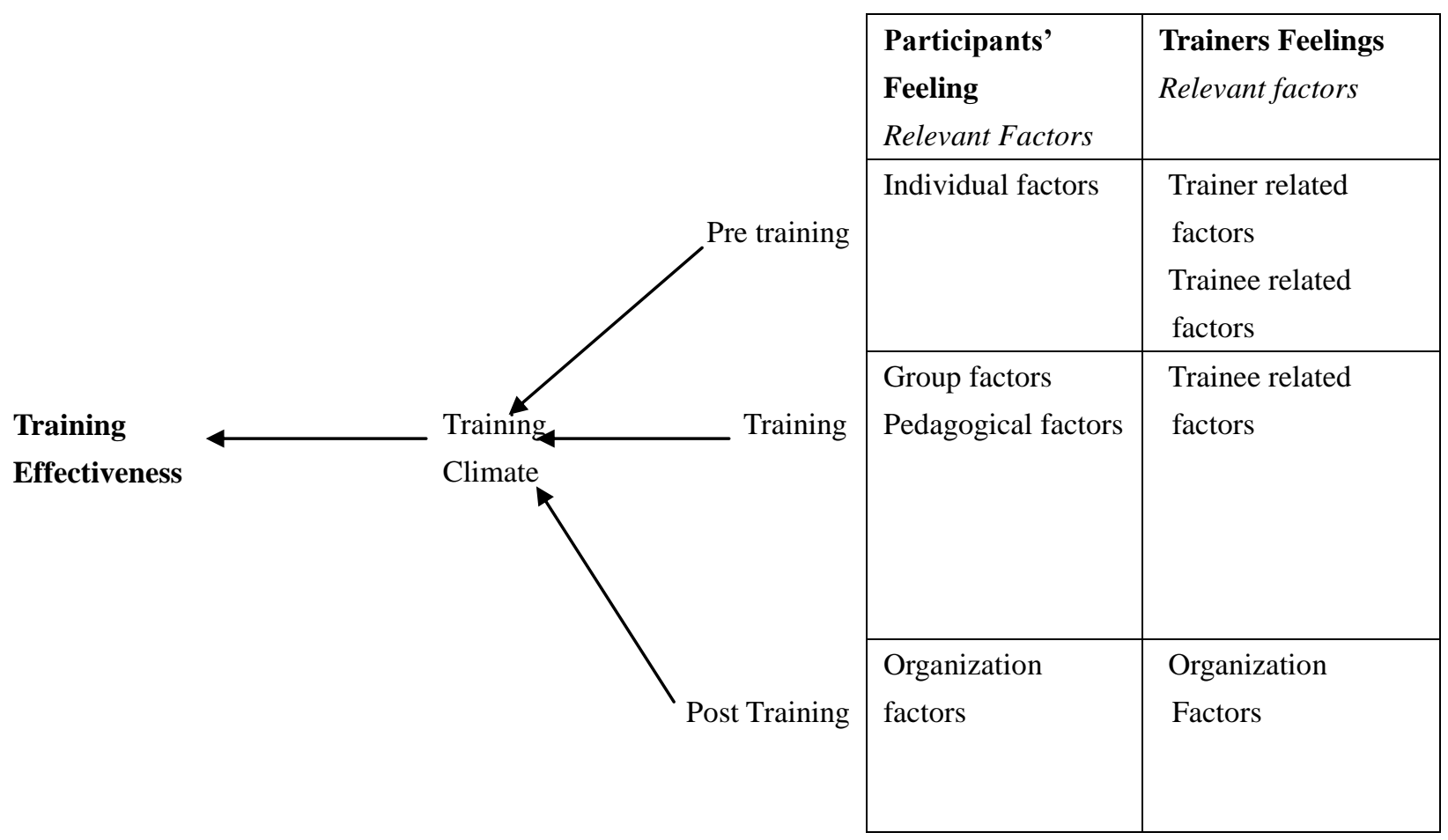

\subsection{Individual Factors}

Individual factors influencing participant's feeling correspond to Pre Training Stage. It leads to the conclusion that to influence individual factors, action has to be taken at pre training stage. For example, if it is found during training that participants' have little interest or required knowledge about the training subject, nothing can be done at the stage. A proper analysis before training can only mitigate the problem to an extent. Certain Trainer as well as Trainee related factors which influence Trainer's feeling corresponds to Pre Training Stage. 
For example, trainer's command over the subject is one such factor about which no corrective action can be taken during training. It is essential to evaluate this before training at Pre Training stage only.

\subsection{Group and Pedagogical Factors}

These factors which influence participant's feelings about training are classified in Training stage. Issues such as structuring, methodology, group dynamics has got direct bearing on the formulation of favorable or unfavorable climate. If we concentrate on structuring of the content, it is clear that the trainer would have some structure in his mind prior to the start of the training program, however, the final structure immerge only during training after he develops some understanding of participant feelings and needs. Trainee related factors which affect the trainer are also embedded in the Training Stage. Prior knowledge about the background of trainees provides trainer with some understanding of trainees' profile, however actual acclimatization takes place only during Training. Even if we know that a group of trainees has prior advanced understanding of the subject, we can not presume that they will behave in a mature manner. To the contrary, they may behave in such a manner which may make the training climate very negative.

The way training is perceived in organization has an impact on learning orientation of participants. If there is non-serious image of training with little chance of application, trainees also during training program will demonstrate insincere behavior. This aspect can not be taken care by either pre training planning or during training stage. In case of trainer if time and resource commitment is minimal, it would lead to disappointment and lack of commitment on the part of trainer also. For example, if trainer perceives that organizational circumstances are not conducive for the implementation of learning imparted through training, it will have an impact on his feelings. These factors are classified with Post Training Stage, though to some extent they should also be taken care of in pre training stage.

\section{Civil Services Training Program}

Training climate leads to effectiveness of training programs. This contention has been tested by analyzing one training program having same content but delivered to two different groups of participants. This case appropriately illustrates the complex interwoven relationship among Training Stages, Training Climate and Training Effectiveness. The case pertains to a premier B School which conducts regular training programs for civil services officers. The programs covered various managerial topics like Human Resource Management, Team Building, Environment and Natural Resource Management, Project Formulation \& Implementation and many others. Programs are for middle and senior level of officers and the objective is to make them abreast with latest in the field and help them in their present jobs. This activity is given high importance in the B School as it is a very prestigious assignment. Institutes' senior professors conduct these programs with the help of renowned outside experts. To demonstrate the impact of Training climate I would be taking example of two programs conducted on Environment and Natural Resource Management for different group of officers. The 
programs were conducted within an interval of nine months with basic course structure, trainer, and pedagogy remaining the same. These programs are referred as Program I and Program II hereinafter. Program I though designed and conducted for the first time was perceived to very successful as per the feedback of participants as well as trainers. However, Program II was considered not very satisfactory by either participants or the trainer and course director. With the help of diagnostic model proposed above, reasons for this asymmetric outcome will be identified and analyzed in the following discussion. An objective and subjective feedback is taken from the participants and comments are taken from the faculty during and after the completion of program. This feedback is summarized in Table IIa and IIb. Two incomplete responses in the first program and three incomplete responses in second program are not taken into consideration.

Feedback is determined to be the best Judge of Training Climate prevailing during the program as it measures the reaction of the participants. Reaction which is the first step of evaluating effectiveness of a training program has been defined as 'The way participants feel or emotionally respond' to the training program, in other words "how well the trainees liked a particular training program." (Kirkpatrick, 1975 \& Philips, 1997) It is clear from the analysis of data depicted in figuring II a, II b, II c whereas first program was very well liked by all; the second one was not very well appreciated. On a three point scale, the mean rating of first program was 2.4 and standard deviation of .50 whereas in case of second program the mean rating is 1.64 and standard deviation is .64. This demonstrates that the first program was broadly appreciated by the participants in comparison to the second program. Higher standard deviation also indicates that in second program the feelings of the participants were divergent and with less mean rating, it can be concluded that the second program did not have desired impact on the trainees. This indicates the prevalence of better (Favorable) training climate during first program compared to second program. Further analysis of subjective remarks given by participants substantiates the point. Content analysis clearly demonstrates that the greater number of participants found the first program interesting compared to second program. Some of the findings are summarized in Table III. In the following discussion, we will analyze the two programs as per the diagnostic model proposed above and identify the factors which led to such a different outcome in similarly structured and delivered program.

\subsection{Program I}

In the first program, half of the participants can be classified as senior, having more than 20 years of experience; others can be categorized as middle level officers. The group had officers from different services i.e. Indian Administrative Services (IAS), Indian Economic Service (IES), Indian Forest Service (IFS), Indian Revenue Service (IRS) and Provincial Administrative Services (PAS). Out of seventeen, three participants were females. During the interaction, it was clear that participants are eager to learn and their knowledge base was similar. These individual factors had appositive impact on the climate. Group factors such as sense of related ness can be gauged from the group exercises and comments of the trainers which clearly demonstrate a sense of team among the group members. Prior association among group members was almost negligible. This may have precluded them form any bias 


\section{I Macrothink}

Enterprise Risk Management

ISSN 1937-7916

2009, Vol. 1, No. 1: E6

towards each other. Training factors such as trainer's ability to relate, timing, structuring were well liked by the participants which is visible from the content analysis of the comments.

Table 2a: Summarized Feedback of Program I

\begin{tabular}{|c|c|}
\hline $\begin{array}{l}\text { Overall Rating by each } \\
\text { participant } \quad(1=\text { poor, } \quad 2= \\
\text { satisfactory, } 3=\text { Good }) n=15\end{array}$ & Remarks \\
\hline 3 & Interesting, good, new \\
\hline 3 & Most effective, very good \\
\hline 3 & $\begin{array}{l}\text { Nicely organized, relevant, exceptionally good, diversified, } \\
\text { and less interactive. }\end{array}$ \\
\hline 2 & $\begin{array}{l}\text { Relevant, diversified knowledge, narrow coverage, poor } \\
\text { faculty selection }\end{array}$ \\
\hline 2 & Residential facility inadequate, lack of practical exposure \\
\hline 3 & Relevant, outstanding, very useful \\
\hline 2 & Well designed, knowledgeable speakers, less interactive, \\
\hline 2 & Enough, good input, galaxy of speakers \\
\hline 2 & $\begin{array}{l}\text { Very good conduct, long duration, narrow coverage, eminent } \\
\text { speakers }\end{array}$ \\
\hline 2 & Poor logistics, good content, repetitive, good faculty, punctual \\
\hline 2 & $\begin{array}{l}\text { Very productive, good faculty, less emphasis on practical } \\
\text { aspect }\end{array}$ \\
\hline 3 & Well structured, expert speakers \\
\hline 2 & Lack of practical exposure, informative, graceful faculty \\
\hline 2 & Well designed good coverage, less practical \\
\hline 3 & $\begin{array}{l}\text { Well organized, reflective process. Very good, triggered } \\
\text { thinking }\end{array}$ \\
\hline
\end{tabular}

Predominant adjectives used are that the program was well structured and faculty was helpful and graceful. However, common complaint was lack of practical exposure which is content specific issue. Trainees' expectation about support they are likely to get from organization is one area where participants were unenthusiastic, as they felt that not much is going to be used in their jobs. (Refer to table 2a). This aspect was also not addressed by trainers also as reflected in the comments of the participants. Overall it can be concluded that individual factors and group factors had positive impact on participant's feelings. Training factors had minor negative impact and organization factors had negative impact on the feelings of the participants.

The factors which influence Trainer's feeling also had mixed composition. Trainer related factors like trainer's command over subject had positive impact. Most of the trainers were expert in their areas and very senior professionals. Trainee related factors also had positive 
impact on the trainer's feelings. Participants were eager to learn and involved in the training program which is demonstrated in the comment given by trainers themselves. However, organization factors had varying influence as some of the trainers felt that in government set up, subject matter of training is not given due priority.

\subsection{Program II}

In the second program on the same topic the composition of group was different. Out of total 17 participants, all are classified as senior as they had more than 20 years of experience. Another, striking point was that all of them belonged to Indian Administrative Service (IAS) it can be assumed that they must have gone through the same kind of learning experience. This would have led to strong prior opinions about the subject.

Table II b: Summarized Feedback of Program II

\begin{tabular}{|c|l|}
\hline $\begin{array}{l}\text { Overall Rating by each } \\
\text { participant } \quad(1=\text { poor, 2= } \\
\text { satisfactory, 3= Good) } \mathrm{n}=14\end{array}$ & \\
\hline 2 & Interesting and useful, good \\
\hline 2 & Well conducted, well covered \\
\hline 1 & Elementary, focus on sensitization \\
\hline 2 & Well structured, extremely good \\
\hline 1 & To theoretical, not adequate for middle level officers \\
\hline 1 & Relevant, content and conduct poor \\
\hline 2 & Useful \\
\hline 1 & Theoretical, faculty selection poor \\
\hline 2 & Poor content selection, good and useful \\
\hline 1 & No interaction, gap in capabilities \\
\hline 2 & Well structured, good faculty selection \\
\hline 1 & Good but theoretical input \\
\hline 2 & Less emphasis on case study and practice \\
\hline 3 & $\begin{array}{l}\text { Very good, informative, interesting and well conducted, good } \\
\text { speakers }\end{array}$ \\
\hline
\end{tabular}

Among group factors, prior association among group members was high which has resulted in strong biases. During the course of program, no team spirit emerged as participants were too immerged in their own thinking. It is also reflected in comments which are very general and lack nuances.

Organizational factors also had negative impact as most of the participants were unenthusiastic about the subject. Trainers' feelings were negatively affected by trainees' behavior and attitude. It was observed by trainers that many a times almost half of the trainees were absent from the training session. Organizational factors also did not have much 
positive impact. (Refer to Tabl1 2b).

\subsection{Analysis and Comparison}

It is clear that major point of difference between first and second program was profile of the trainees. This factor was not considered by the course director and the trainees while designing the program which led to prevalence of unfavorable climate during the training program.

Table 2c: Comparison of Program I and II

\begin{tabular}{|l|l|l|}
\hline & Mean & Standard Deviation \\
\hline Program I & 2.40 & 0.50 \\
\hline Program II & 1.64 & 0.63 \\
\hline
\end{tabular}

Comparison of the program emphasizes the importance of pre training and post training stage in the success of the training program. It also substantiates the proposed diagnostic model. Mean rating (2.40) of Program I is greater compared to mean rating (1.64) of Program II. Standard deviation of Program II (0.63) is higher compared to Program I (0.50). (Refer to Table 2c).

Table 3: Content Analysis of Program I and II

\begin{tabular}{|l|l|l|}
\hline & $\begin{array}{l}\text { Number of Participants } \\
\text { giving Positive comments }\end{array}$ & $\begin{array}{l}\text { Number of Participants } \\
\text { giving Negative comments }\end{array}$ \\
\hline Program I & 12 & 3 \\
\hline Program II & 7 & 7 \\
\hline
\end{tabular}

Analysis of comment made by trainees also show that Program I was a bigger success compared to Program II as number of participants making positive comment is greater in Program I (12) compared to Program II (7). Number of participants making negative comments is lesser in Program I (3) compare to Program II (7). (Refer to Table 3).

The case also shows that if problems are identified during training stage which have origin in pre training stage or post training stage, it is difficult to take any significant corrective actions. During the training program, the senior most participant kept on giving names of professionals, he wanted to be invited for the training. However, at that stage nothing could be done. The right time to take/give these kinds of suggestions is pre training stage.

\section{Conclusion}

Success of training is not merely dependent on quality of trainer rather it is the result of cumulative sum of trainer, trainee and organizational efforts and commitment. Primary responsibility lies with the training manger, as representative of organization they should 


\section{Macrothink}

ensure proper pre training planning as well as post training support. They should coordinate closely with trainer, be it in house or an outsider, so as to make him aware of the objectives as well as facilitate him in delivery of training. Training as a function can improve its image only when all concerned will show high commitment and avoid trivialization. Proposed Diagnostic model can help in evaluating a training program from training climate perspective as well as help in designing effective training program. All three stages of training influences training climate which in turn has an impact on training effectiveness. For successful training programs, it is essential to take an integrated view of training stages and training climate.

\section{References}

Budhwar, P., \& Sparrow, P., (1997). Evaluating levels of strategic integration and development of human resource management in India. International Journal of Human Resource Management, 15, 2, 476-494.

Fill, C., \& Mullins, L., (1990). The effective management of training. Industrial and Commercial Training, 22, 1.

Kirkpatrick, D L., (1975).Techniques for evaluating programs, Parts 1, 2, 3 and 4. Evaluating Training Programs, ASTD,

Lynton, R.P. \& Pareek, U., (1990). Training for Development, Sage Publications, pp 184-186, 1990

Lynton, R.P. \& Pareek, U., (2000). Training For Organizational Transformation. Sage Publications, pp.14-16, and 28.

Nickols, F., (1992). Evaluating training - there is no cookbook approach. ASTD Tool Kit, Washington, D.C., ASTD Press.

Phillips, J.J., (1997). The Return on investment in Phillips, J.J. (ed.), Human Resource Development, Washington, D.C. ASTD Press.

Bramley, P., (1989). Effective training, Journal of European Industrial Training. 13, 7.

Crosbie, R., (2005). Learning the soft skills of leadership. Industrial and Commercial Training, 37, 1, 45-51.

Virmani, B.R. \& Seth, P., (1985). Evaluating management training and development, New Delhi : Vision Books (Chapter 4) 